\title{
Production and optimization of hand disinfection solution based on the World Health Organization formulation: Short Communication
}

\author{
Farshid Abedi ${ }^{1}\left(\mathbb{D}\right.$, Mohammad Hasan Namaei ${ }^{2}$, Zahra Hamidi ${ }^{3}$, \\ Maryam Soltani $^{3}$ iD), Zahra Kiani ${ }^{4}$ \\ ${ }^{1}$ Infectious Diseases Research Center, Department of Infectious Diseases, School of Medicine, Birjand University of Medical \\ Sciences, Birjand, Iran. \\ 2 Infectious Disease Research Center, Department of Medical Molecular \& Genetics, School of Medicine, Birjand University of \\ Medical Sciences, Birjand, Iran. \\ ${ }^{3}$ Razi Clinical Research Development Unit (RCRDU), Birjand University of Medical Sciences, Birjand, Iran. \\ ${ }^{4}$ Corresponding author: Medical Toxicology and Drug Abuse Research Center (MTDRC), Department of Pharmacology, , School \\ of Medicine, Birjand University of Medical Sciences, Birjand, Iran. \\ Tel: +9832381930 \\ Fax: +9832381509 \\ Email: kiani.za@gmail.com
}

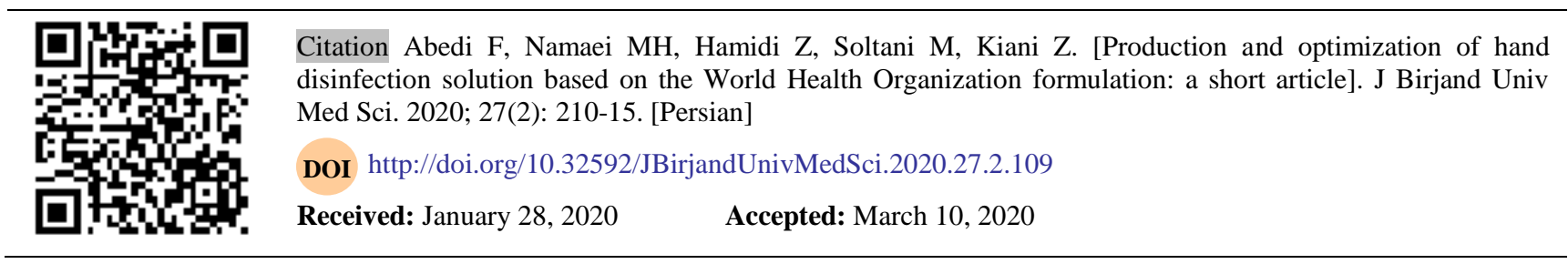

\begin{abstract}
Hand hygiene is the most effective, simplest, and least expensive way to prevent the spread of hospital infections. Hand hygiene needs an ingredient that shows effectiveness in reducing microbial load in a way; alcohol-based hand rubs have more effective, fast and long-lasting disinfection than other antiseptics. The aim of this study was to prepare and optimization of an alcohol-based hand rub solution recommended by World Health Organization (WHO) to reduce expenses in sanction situations and also enhance the satisfaction and tolerability of the product.
\end{abstract}

Key Words: Alcohol-Based Hand Rub; Disinfection; Optimization; Production; World Health Organization 


\title{
توليل و بهينهازى محلول ضلعفونى دست بر يايه فر مو لاسيون سازمان بهاشت جماذى: يك مقاله كوتاه
}

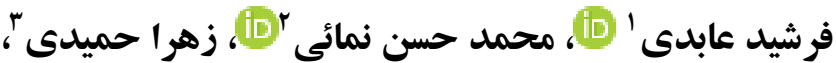

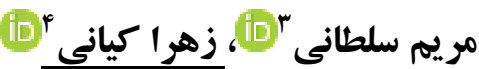

\begin{abstract}
جككيده

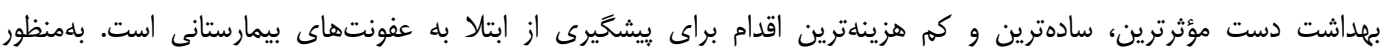

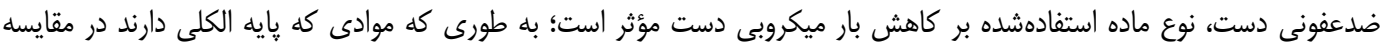

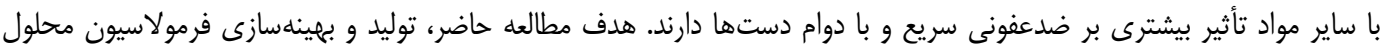

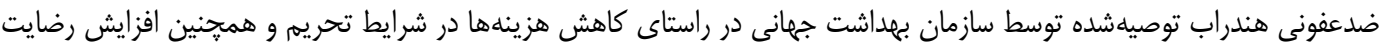

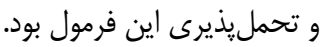

وازههاى كليدى: هندراب يايه الكلى؛ ضدعفونى; بهينهسازى؛ توليد؛ سازمان بهداشت جهانى مجله علمى دانشكاه علوم يزشكى بيرجند. و qسا؛ دريافت:
\end{abstract}

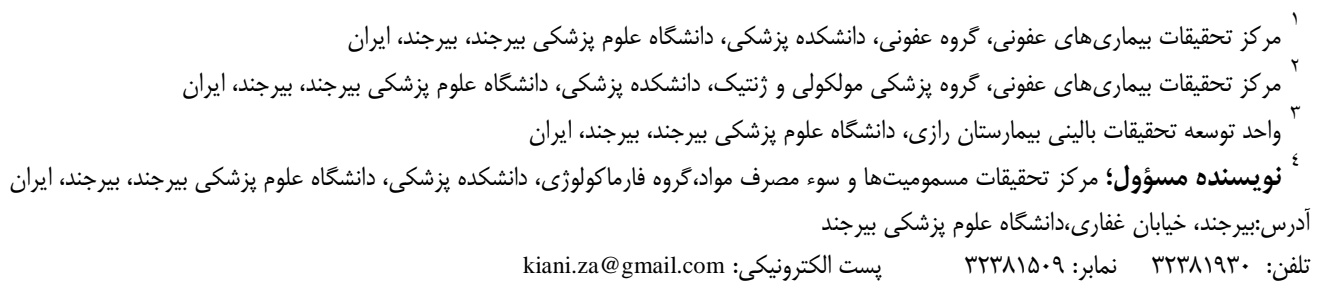


بهدليل تحريم و به دنبال آن كرانى و كمبود فرآوردههاى مقلdod تجارى ضد عفونى دست، كميته كنترل عفونت بيمارستان

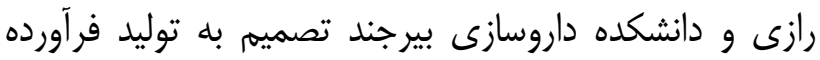

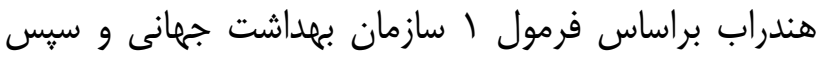

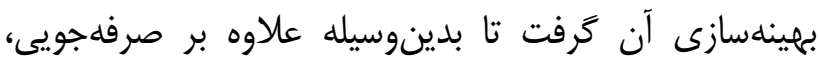

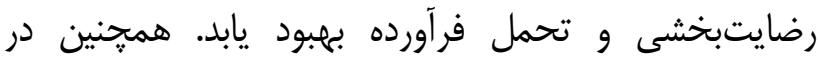

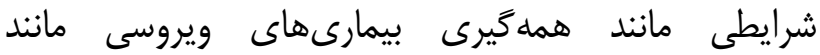
كروناويروس، توليد محلى اين فرآورده مىتواند كمبود راني

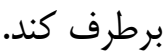

\section{روش تحقيق}

\section{مواد و دستخاهها:}

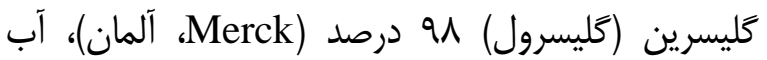
اكسيزنه هـ درصد (برندشيمى، ايران)، آب مقطر دو بار تقطير،

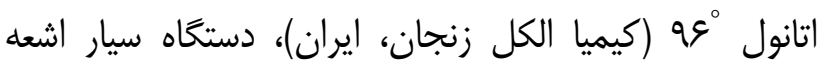

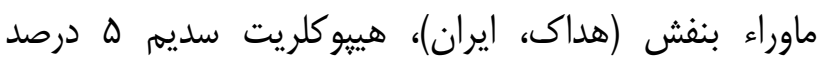
(ياكسان، ايران)، منتول (مبتكران شيمى، ايران)، الكلسنج

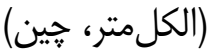

\section{أمادهسازى فضاي ساخت:}

محل ساخت اين محلول، اتاق استريل بيمارستان رازى ساخى

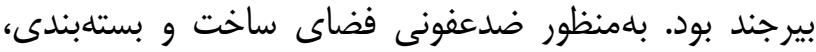

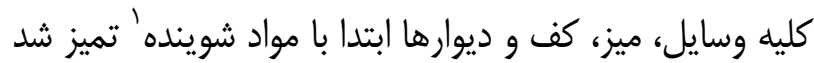
و سيس با كلر / /. درصد كه با تركيبنمودن يك وابن واحد

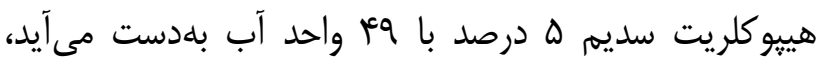

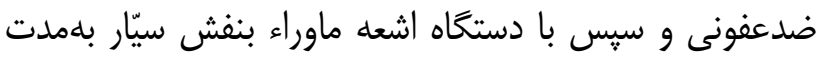

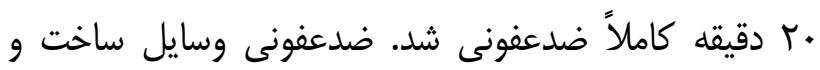

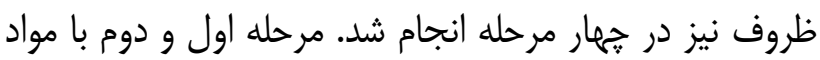
شوينده و آبكشى، مرحله سوم غوطهورى درى در هييوكلريت سديم / / درصد و مرحله جهارم غوطهورى در آب و و سيس آبكشى با آب مقطر انجام شد. براى رعايت نكات غرطات استريل

\footnotetext{
${ }^{1}$ Detergent
}

بهداشت دست، عامل اساسى در جهت كاهش كلونيزهشدن ميكرواركانيسمها و عفونت همه افراد بلختصوص

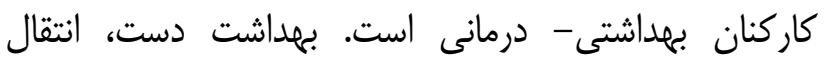
ميكرواركانيسمها را كاهش داده و بنابرابراين ابتالا به بيمارى

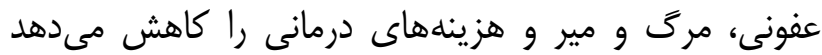
(1). بهداشت دست با شستشو با آب و صابون، شستشو بانيا

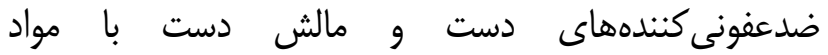
ضدعفونى كننده مانند: محلول، زل و فومهاى باى با پايه الكلى و غيرالكلى امكانيذير (Alcohol-Based Handrubs)

فرآوردههاى هندراب بايه الكلى، بيشتر از بقيه مقبوليت

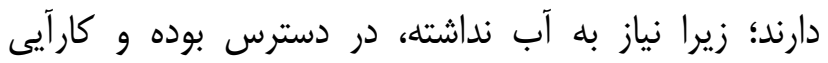

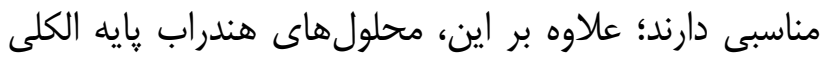

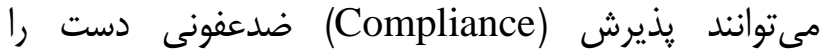

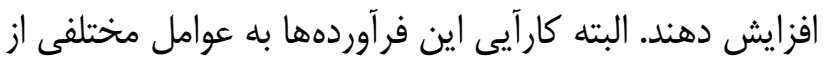
جمله مقدار مصرف، نحوه كاربرد و دفعات استفاده بستخى إنى دارد و همجنين در مواردى كه بار ميكروبى دست بارئ بالا باشده،

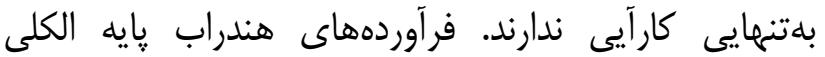

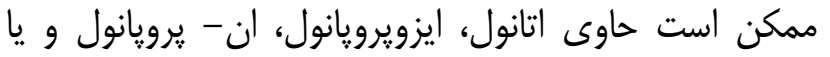
تركيبى از دو ماده باشند. مكانيسم اثر اين تركيبات، انعقاد إناد

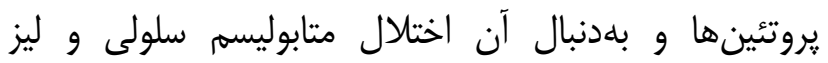

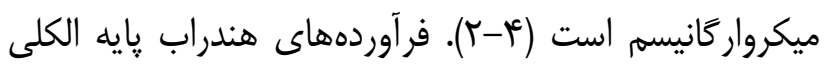

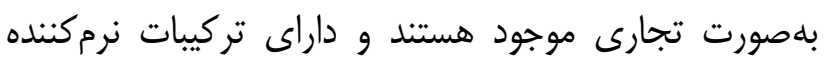
مختلف با درصدهاى متفاوت، زمان استفاده و قيمت متفاوت درات

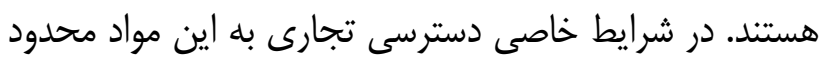
مىشود و يا مصرف آنها بهشدت افزايش مى ديابد. اين شرايط

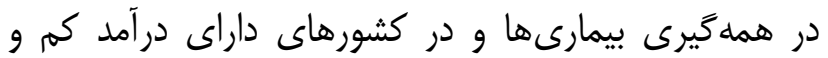

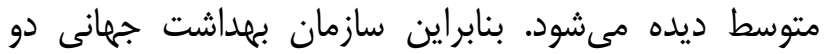

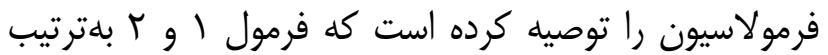

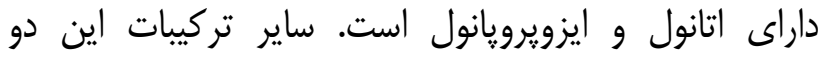
فرمول آب اكسيزنه و كليسرين مىباشد (ه). در مطالعه حاضر 


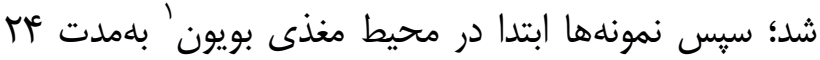

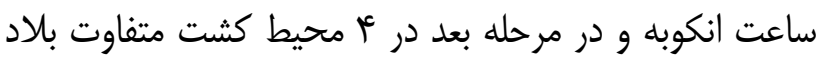

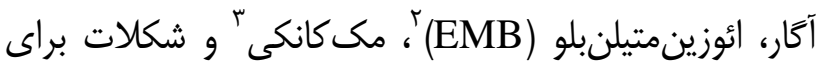

$$
\text { تشخيص باكترىها كشت داده مىشد. }
$$

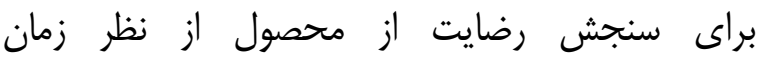

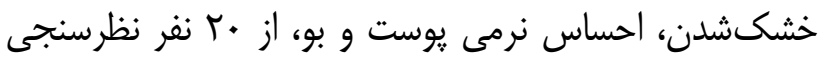

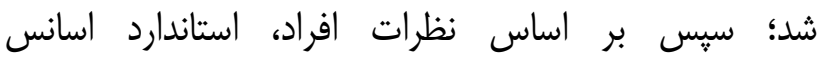
فرآوردههاى موضعى و نتايج آزمايشهاى ميكر نيكروبى، درصد

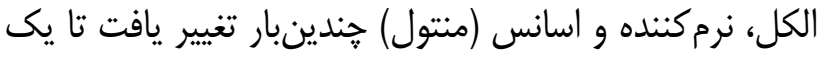

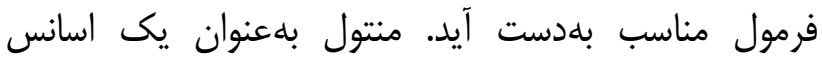

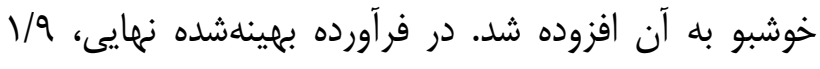

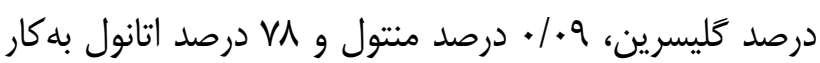

در نهايت هزينه ساخت محلولها محاسبه شد كه با

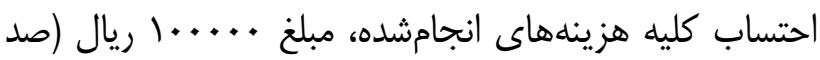

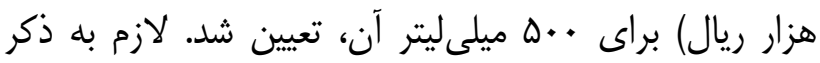
است كه قيمت در مردادماه يوسا محاسبه شده است.

\section{يافته ها و بحث}

با وجود اهميت زياد ضدعفونى دست در كاهش انتقال

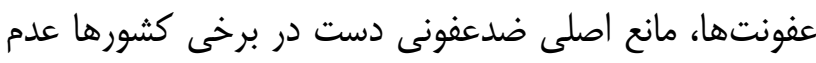
دسترسى مداوم به محصولات ضدعفونى هندراب با قيمت إنى مناسب است (צ)؛ بنابراين در مطالعه حاضر، فرآورده هندو هندراب

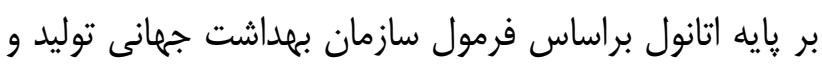

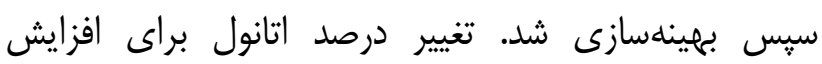

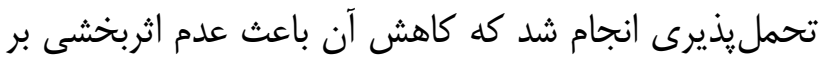

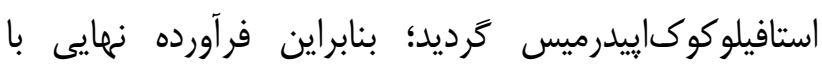
غلظت VVدرصد آماده شد. دليل استفاده از اتانول، قيمت كمتر

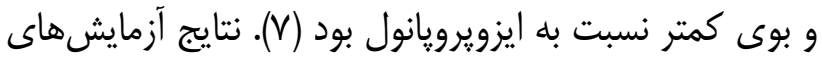

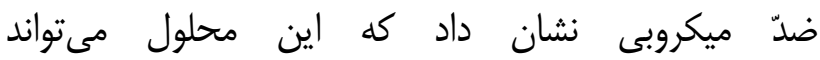

\footnotetext{
${ }^{1}$ Nutrition broth (Bouillon)

${ }^{2}$ Eosin Methylene-Blue

${ }^{3}$ MacConkey
}

يرسنل، كليه افرادى كه وارد محدوده تميز مىشدند كان،

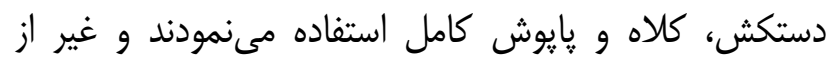
افراد ذكرشده هيج فردى حق ورود نداشت.

\section{تهيه محلول:}

در اين مطالعه ابتدا فرمول مورد تأييد سازمان بهراشت

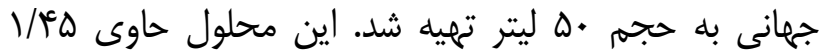
درصد كليسرين بلعنوان نرمكننده است و براى از بين بردن لهن

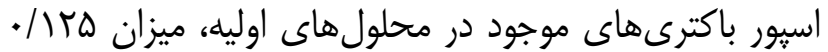

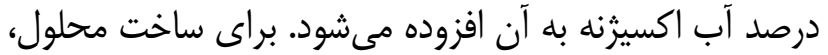

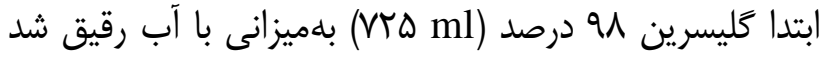
كه بتوان در تانك اصلى، مخلوطكردن را بهخوبى انجام داد.

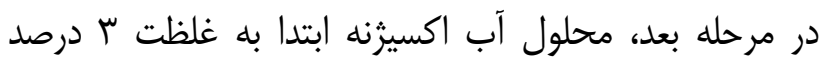

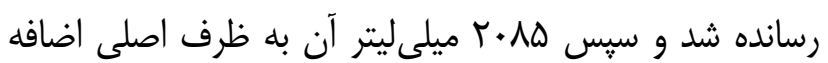

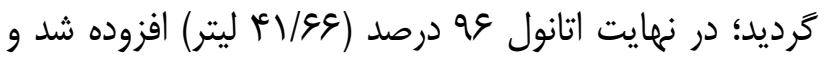

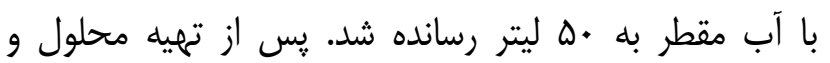

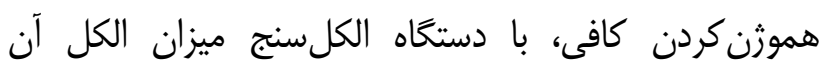
مشخص شد؛ سيس در ظروف نيهليترى بستهبندى گرديد.

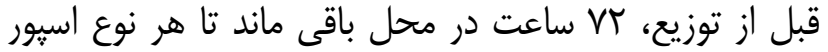

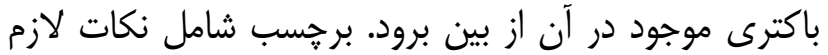

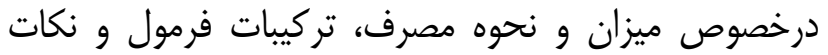
ايمنى طراحى و برجسب گُخارى انجام شد.

\section{تعيين كارآيى، رضايت و قيمت:}

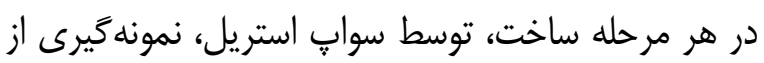
سطوح كار، ظروف ساخت، مواد اوليه و فرآورده آماده كرفته سته مىشد و با انجام آزمايشهاى ميكروبى در، درو آزمايشگاه

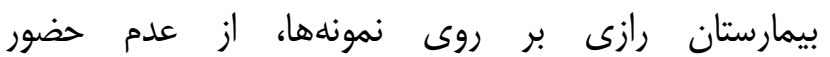
ميكروار كانيسمها در هر مرحله اطمينان حاصل مى رَّديد. در

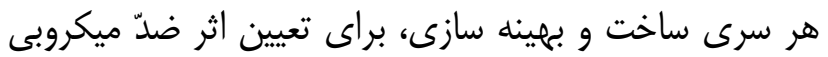

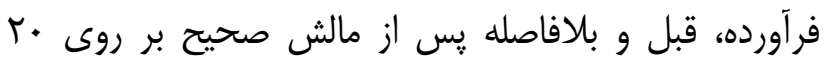

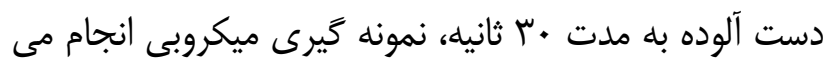




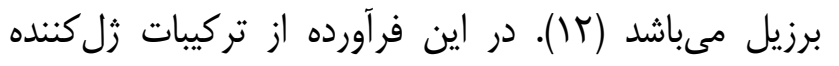

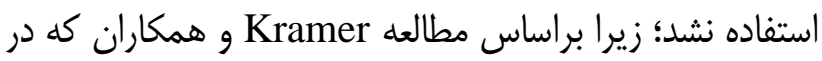

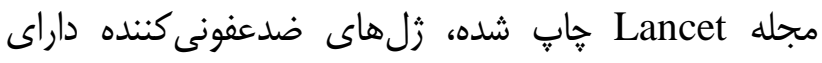

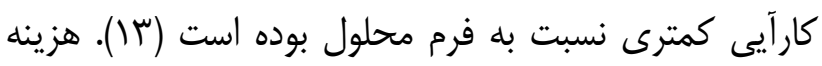

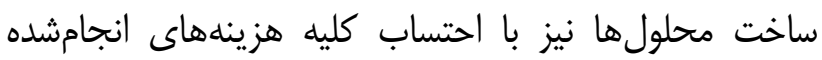
نسبت به كمترين قيمت محلولهال مالى مشابه در زمان انجام

$$
\text { مطالعه، أ تا ه هبرابر كمتر بود. }
$$

\section{نتيجه كيرى}

با توجه با سهولت تهيه، كار آيى و نيز كاهش هزينهها مى

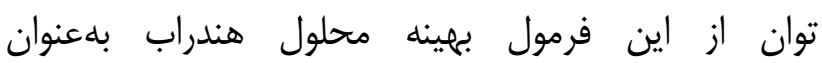
ضدعفونى كننده دست كاركنان بيمارستانى و بيماران استفاده

\section{تقدير و تشكر}

نويسندكان مقاله از يرستاران بيمارستان رازى و نيز از

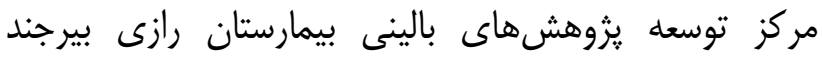
بلهخاطر مشاوره و همكارى، تشكر و قدردانى مىنمايند.

\section{تضاد منافع} نويسندكان مقاله اعلام مى دارند هيج كَّنه تضاد منافعى در يزوهش حاضر وجود ندارد.
ميكرواركانيسمهاى دست كاركنان را از بين ببرد. مطالعات

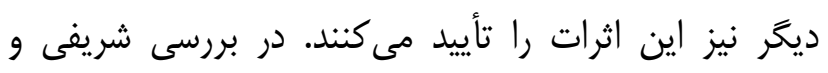

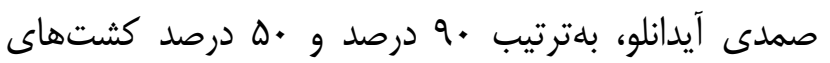

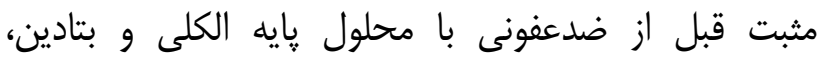

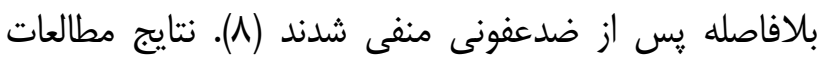
ديكر نيز نشان داده است كاهش بار ميكروبى پيس از استفاده

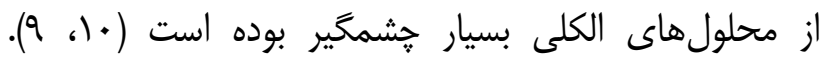

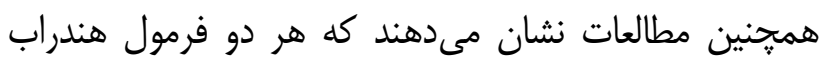

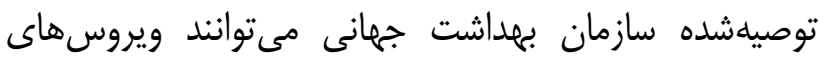

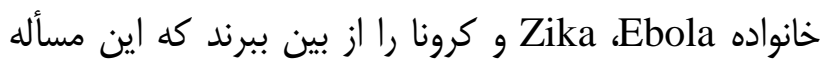

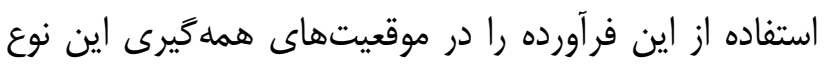

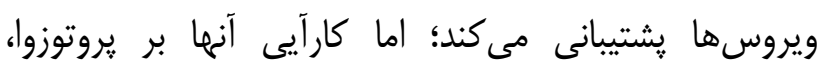

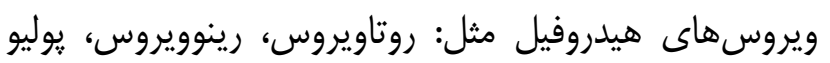

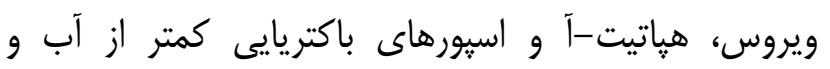

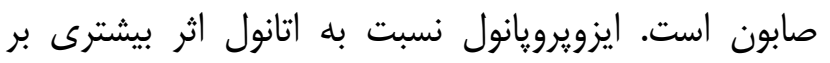

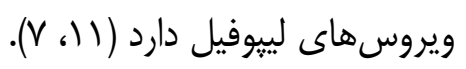

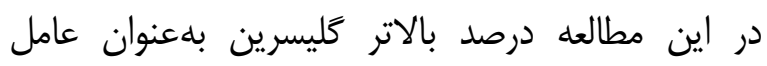

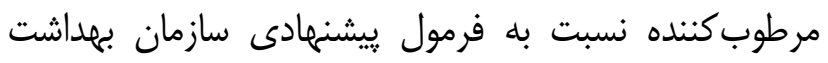

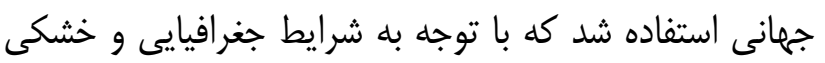

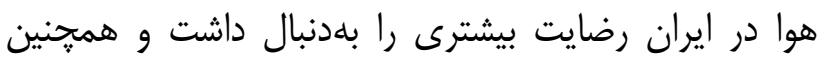

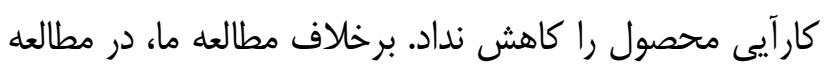
Menegueti

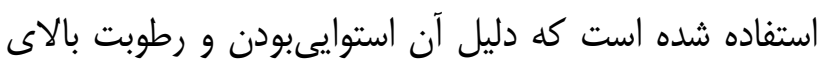

1- Allegranzi B, Pittet D. Role of hand hygiene in healthcare-associated infection prevention. J Hosp Infect. 2009; 73(4): 305-15. doi: 10.1016/j.jhin.2009.04.019.

2- Greenaway RE, Ormandy K, Fellows C, Hollowood T. Impact of hand sanitizer format (gel/foam/liquid) and dose amount on its sensory properties and acceptability for improving hand hygiene compliance. J Hosp Infect. 2018; 100(2): 195-201. doi: 10.1016/j.jhin.2018.07.011.

3- Vermeil T, Peters A, Kilpatrick C, Pires D, Allegranzi B, Pittet D. Hand hygiene in hospitals: anatomy of a revolution. J Hosp Infect. 2019; 101(4): 383-92. doi: 10.1016/j.jhin.2018.09.003.

4- Hugonnet S, Perneger TV, Pittet D. Alcohol-Based Handrub Improves Compliance with Hand Hygiene in Intensive Care Units. Arch Intern Med. 2002; 162(9): 1037-43. doi:10.1001/archinte.162.9.1037

5- Boyce J, Chartier Y, Chraiti M, Cookson B, Damani N, Dharan S. WHO guidelines on hand hygiene in health care. Geneva: World Health Organization; 2009. 
6- World Alliance for Patient Safety. WHO guidelines on hand hygiene in health care (advanced draft): a summary, clean hands are safer hands. Geneva, Switzerland: World Health Organization; 2005.

7- Gold NA, Avva U. Alcohol Sanitizer [Internet]. Treasure Island (FL): StatPearls Publishing; 2018 [cited 2020 Jan 1]. Available from: https://www.ncbi.nlm.nih.gov/books/NBK513254/

8- SHarifi N, Samadi Aydenlo N. Comparison of antiseptic effect of Decosept and Povidin Iodine on hand skin normal flora. Urmia Nurs Midwifery J. 2008; 6(3): 123-6. [Persian]

9- Gupta C, Czubatyj A, Briski L, Malani A. Comparison of two alcohol-based surgical scrub solutions with an iodinebased scrub brush for presurgical antiseptic effectiveness in a community hospital. J Hosp Infect. 2007; 65(1): 65-71. DOI: 10.1016/j.jhin.2006.06.026

10- Masakini F, Noorbakhsh F, Honarmand Jahromi S. Comparison between the efficacy of hand washings with waterless hand hygiene in hospital nurses. Journal of Health and Safety at Work. 2017; 7(4): 353-62. [Persian]

11- Siddharta A, Pfaender S, Vielle NJ, Dijkman R, Friesland M, Becker B, et al. Virucidal Activity of World Health Organization-Recommended Formulations Against Enveloped Viruses, Including Zika, Ebola, and Emerging Coronaviruses. J Infect Dis. 2017; 215(6): 902-6. doi: 10.1093/infdis/jix046.

12- Menegueti MG, Laus AM, Ciol MA, Auxiliadora-Martins M, Basile-Filho A, Gir E, et al. Glycerol content within the WHO ethanol-based handrub formulation: balancing tolerability with antimicrobial efficacy. Antimicrob Resist Infect Control. 2019; 8: 109. doi: 10.1186/s13756-019-0553-z

13- Kramer A, Rudolph P, Kampf G, Pittet D. Limited efficacy of alcohol-based hand gels. Lancet. 2002; 359(9316): 1489-90. DOI: 10.1016/S0140-6736(02)08426-X 